\title{
UMA NOVA SOLUÇÃO PARA UM VELHO PROBLEMA: CONTROLE DE ESTOQUES COM O SMARTGLASS RIVERSTOCK
}

\author{
Claudio de Souza Rocha Junior (UFRRJ) claudiodesouzarochajunior@gmail.com \\ Adilson Vilarinho Terra (UFF) adilsonvilarinho@id.uff.br \\ Miguel Ângelo Lellis (UFF) miguellellis@id.uff.br \\ Marcos dos Santos (IME) marcosdossantos@ime.eb.br
}

\section{Resumo}

Partindo do princípio da grande importância do estoque para as organizações, idealizou-se uma solução aplicável em larga. Tal solução pode ser aplicada em larga escala sem a necessidade de alteração na estrutura organizacional ou implementação de treinamentos com o corpo de funcionários. O presente estudo está fundamentado na metodologia PBL (Problem Based Learning), onde foi proposta uma solução para um problema geral de logística: contabilização de estoque. Os resultados alcançados da estruturação foram positivos, demonstrando a viabilidade dentro do mundo real, não estando limitado apenas ao metafísico. Por conseguinte, a sociedade é beneficiada como um todo através de otimização de seus recursos, evitando desperdícios e gastos desnecessários.

Palavras-Chaves: IoT, Hardware, Gestão de Estoque, Patente de Produto.

\section{Introdução}

As organizações - em especial as produtoras de artefatos físicos - possuem um fluxo de produção e entrega tecnicamente explicitado na logística empresarial.

Não obstante, apesar de toda a complexidade estruturada dos sistemas logísticos e seus estudos, estoques com erros de contagem são uma realidade de todas as empresas (nacionais e internacionais), o que é de uma compreensibilidade aceitável, afinal, a variar do segmento da organização, tratam-se de peças mínimas até grandes maquinários que precisam estar corretamente quantificados em uma matriz (de extensão .xls ou desenhada à mão em um caderno específico, a depender do sistema adotado no ambiente).

Esta grande dispersão resulta em duas consequências negativas, originadas de parâmetros fundamentais para a sustentabilidade de uma organização: faturamento e eficiência. 
Em longo prazo, erros periódicos de contagem de estoque tomam forma nos relatórios financeiros como perdas significativas - e, por vezes, até imperceptíveis, mas de grande poderio se somadas todas as variações de uso - . Então, buscando aumentar o faturamento, o gestor ou responsável pelo sucesso financeiro da organização busca alternativas por vezes tradicionais, como um plano de ação para captação de novos clientes ou política de redução de custos.

As soluções mencionadas acima são em sua maioria eficazes, porém, pouco eficientes, uma vez que o problema se encontra em áreas não mencionadas no plano de ação (como perdas subsequentes de produtos no estoque por motivos variados), resultando, conseguintemente, em perdas maiores, sendo novamente solucionadas de forma eficaz, mas pouco eficiente.

Portanto, buscando o paralelo entre ambos, buscou-se uma solução capaz de ser, simultaneamente, eficiente e eficaz, onde os parâmetros de tomada de decisão sejam mais bem mensurados a partir de relatórios bem definidos de setores com alta volatilidade de variáveis (como a logística).

A solução foi batizada de "Riverstock", união de parte nome da empresa RIVERDATA SOLUCOES EM TECNOLOGIA ME., responsável pelos primeiros testes e criações, e a palavra "stock", "estoque" na língua inglesa.

A premissa está na utilização de smartglasses (óculos inteligentes) acessíveis e de $U X$ (experiência do usuário) intuitiva, a serem aplicados nos responsáveis pela gestão de estoque no chão de fábrica, de forma em que estes sejam os "olhos" que estarão a todo tempo monitorando o estoque de forma automática, sem a necessidade de qualquer treinamento ou alteração na estrutura organizacional da empresa em questão.

\section{Descrição do problema}

\subsection{Considerações gerais}

Em síntese, trata-se da representação do impacto causado nas organizações através de um estoque bem gerenciado e contabilizado (ou não), onde grande parte do planejamento envolvendo o sucesso organizacional possui o estoque como um dos pilares fundamentais.

Seguindo a Figura 1, a estruturação do mapa cognitivo dar-se-á através da seguinte maneira: 
Figura 1 - Mapa cognitivo sobre a dinâmica da gestão de estoque

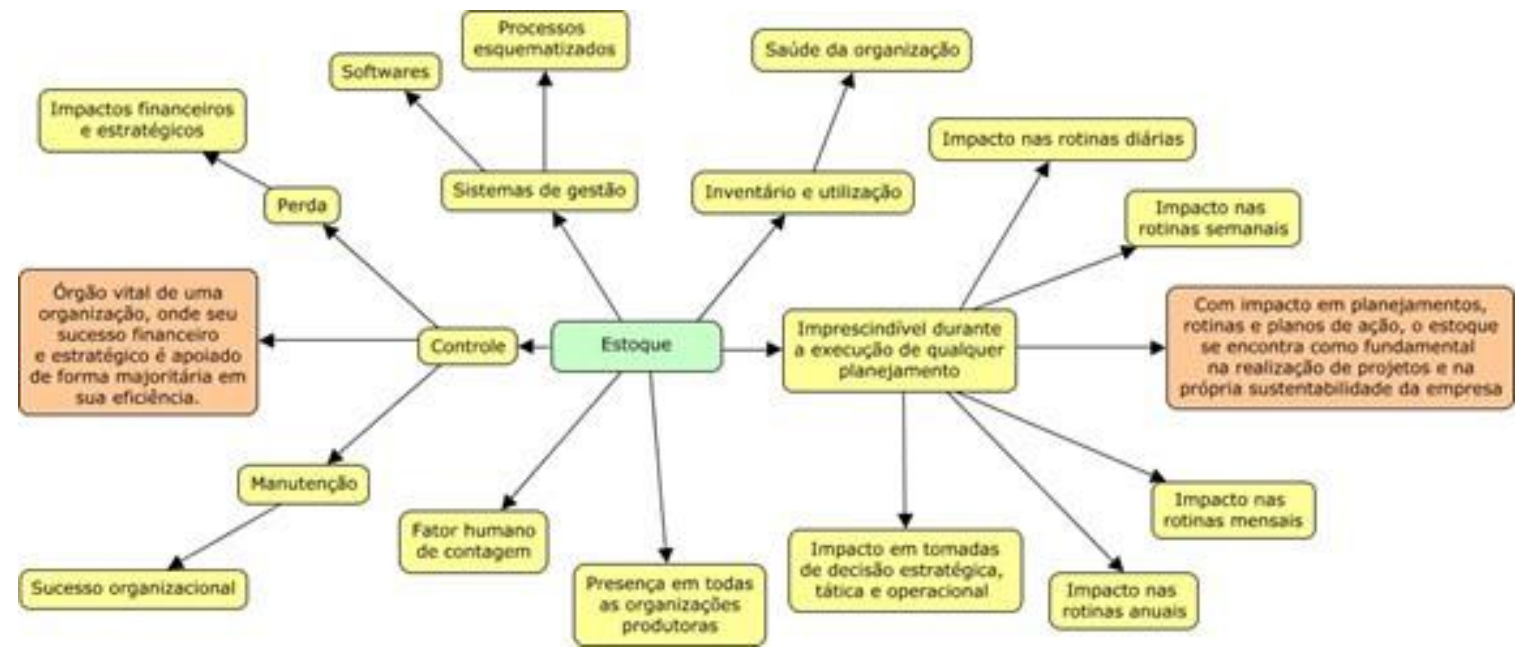

Fonte: Autores (2021)

\subsection{Considerações específicas}

Trata-se de uma abordagem sistêmica dentro das organizações que possuem o conceito de estoque aplicado na prática, utilizando espaços físicos reservados em seu layout para armazenagem de posse de um agente econômico.

Sejam suprimentos, materiais, produtos acabados ou inacabados, esta abordagem infere a função dos estoques além da regulagem do fluxo de materiais ou amortecimento na diferença entre entradas (input) e saídas (output) dos objetos em foco, adentrando em sua influência e poderio na tomada de decisão rotineira até chegar nos pilares estratégicos, com estratégias adotadas por membros da alta administração.

\section{Fundamentação teórica}

Uma empresa é mantida segundo a demanda de algum produto ou serviço. Oliveira et al. (2016) apontam os estoques como itens relevantes, parte de qualquer ramo de negócio, desde a área varejista (atacadista, serviços) até em residências, sendo a quantidade um valor independente. A gestão de estoques é referida ao ato de gerir "recursos ociosos" detentores de 
valor econômico e destinados ao suprimento de necessidades futuras acerca de material dentro das organizações. (COSTA, 2017).

Martelli e Dandaro (2015) inferem o gerenciamento de estoque como a verificação de produtos guardados, onde em sua organização deve-se ter o conhecimento de datas para efetuação de compras, identificação e classificação correta de produtos. Em síntese, o controle de estoque indica quais ações são necessárias para atingir os objetivos organizacionais, partindo do contexto do estoque.

Souza, Santos e Silva (2017) entendem estoque como "uma quantidade de bens com boa aparência, podendo ser matérias-primas, produtos em mudanças ou produtos que estão prontos". No caso de produtos (em específico, os produtos físicos), é essencial que o estoque seja bem controlado. Esta função de controle é de extrema importância pois está relacionada ao nível de precisão da demanda prevista, independentemente do tempo ou nível organizacional utilizado como parâmetro.

De acordo com Paoleschi (2018, p.54): "Uma empresa deve cuidar da gestão de estoques como o principal fundamento de todo o seu planejamento tanto estratégico como operacional, pois um controle correto de estoques elimina desperdícios: tempo, custo e espaço."

Não apenas a título de exposição, é necessário que exista controle no estoque, uma vez que “O controle de estoque é de grande valia para as empresas, pois com ele é possível fiscalizar e gerir a entrada e saída de produtos produzidos e/ou vendido, ou seja, registra e controla tudo o que entra e saí da empresa. Esse controle ajuda a empresa a fazer estimativas de produção, venda, pedido dos fornecedores e até mesmo descobrir quais produtos que são despachados mais rapidamente.” (SILVA;RABELO, 2017, p. 254).

Estes conceitos estão relacionados também à localização física dos produtos - ou materiais - em questão, ou, segundo BRANDALISE (2017): “A localização dos materiais em estoque deve ser fácil e precisa, com identificação dos materiais e todos os itens deve ter endereço certo." Há de ser compreendido que o estoque guarda uma parte considerável de capital, portanto, toda e qualquer forma de evitar desperdícios e tornar seu uso eficiente é válida para o crescimento da organização. Como exemplifica Fenerich (2016, p.138): “Os sistemas de controle de estoque têm a função de equilibrar os custos de estoque e seus parâmetros fundamentais, como quantidade mínima e máxima, tempo de reposição, custo de armazenagem e custo de pedidos.” A partir do ponto vital representado na boa (ou má) gestão de estoque de uma organização, pode-se inferir fatores críticos de sucesso a partir 
dos planejamentos realizados com os dados obtidos nesta mesma gestão: "Planejar é essencial para que se obtenham resultados favoráveis para a administração de uma empresa, onde os resultados tendem a ser positivos e satisfatórios.”, Dandaro (2015, p.176).

Infere Lélis (2016, p. 62): "Um estoque bem controlado e bem gerenciado pode trazer várias vantagens para as empresas da mesma forma que um estoque negligenciado vai significar uma serie de riscos, como a falta do produto ou serviço ao cliente ou custos elevadíssimos em virtude de estoque ocioso.”, portanto, exigir informações extremamente precisas, detalhadas e atualizadas trata-se de um ponto essencial para o gerenciamento de estoques.

Existem diversas teorias criadas para facilitar e sistematizar a gestão de estoque, visando atingir resultados melhores e mais assertivos, como o PEPS - ou FIFO -, para Pedrosa (2016), a preferência está nos produtos há mais tempo em estoque. Na UEPS - ou LIFO -, Dantas (2015) sugere que os produtos há menos tempo em estoque devem ter preferência de saída.

Há também o Just in time, ferramenta voltada para diminuir o estoque da melhor forma possível, em todos os níveis, sendo um sistema controlador do estoque onde nada é fornecido, conduzido ou produzido antes da hora correta, esta, denominada pela demanda (Pedrosa, 2016).

Estes conceitos teóricos existem para aumento da eficiência em paralelo à redução de custo de manutenção. Os custos de manutenção de estoque são os relacionados a todos os custos necessários para manter uma $\mathrm{X}$ quantidade de mercadorias por um período $\mathrm{Y}$ de tempo (Onde X e Y são variáveis), portanto, o custo de oportunidade é um parâmetro existente por conta da imobilização de capital, que poderia ser utilizado de outra maneira - inside/outside business -. Há também os custos associados aos seguros, impostos, custos de armazenagem e quantidade propriamente ditos, todos associados ao risco de perder, e estes, relacionados à deterioração, obsolescência, dano ou furto. (SOUSA et al, 2017).

Por conseguinte, visando à melhoria de processos, há a criação de ferramentas voltadas para diversos fins, como a 5S, ferramenta de organização do ambiente de trabalho, organização de materiais e descarte de componentes desnecessários

Também a utilização da curva ABC (Aragão et. Al, 2016) permite que a eficiência no controle de estoques seja uma realidade, pois, através da mesma, a identificação da necessidade de giro 
é possível, o que facilita consideravelmente a tomada de decisão para a escolha de qual produto deve ser levado em consideração quando as compras são efetuadas pela organização.

A tecnologia de informação no âmbito empresarial permite a mudança de ideias e conceitos acerca da administração, bem como seu uso deve ser aplicado a favor do estoque, com priorização de qualidade e quantidade, visando o controle do conhecimento alinhado ao atendimento da demanda. (DANTAS, 2015).

Como exemplo, é possível citar o sistema ERP como software incorporado nos mecanismos de gestão da empresa que proporciona reunir num único sistema as soluções administrativas de vários departamentos da instituição, acabando por dispersar a necessidade do uso de várias ferramentas paralelas utilizadas na organização.

Há também o NEX, que gera relatórios por meios da curva $\mathrm{ABC}$, facilitando o processo de análise de produtos ao classificar de acordo com o grau de rotatividade.

A junção da tecnologia de informação aplicada em estoque com seu gerenciamento corretamente realizado permite customização do tempo e desempenho nas vendas (Teixeira \& Vernini, 2016), o que influencia no faturamento, bem como na redução de custos monetários significativos.

\subsection{Análise bibliométrica}

O assunto se encontra numa onda notória de discussões dentro da comunidade acadêmica acerca dos termos "Gestão" e "Produção", conforme representado na análise bibliométrica apresentada por intermédio dos gráficos presentes na Figura 2:

Figura 2 - Análise bibliométrica dos termos "Gestão" e "Produção"

Total accesses by year and month

Gestão \&amp; Produção

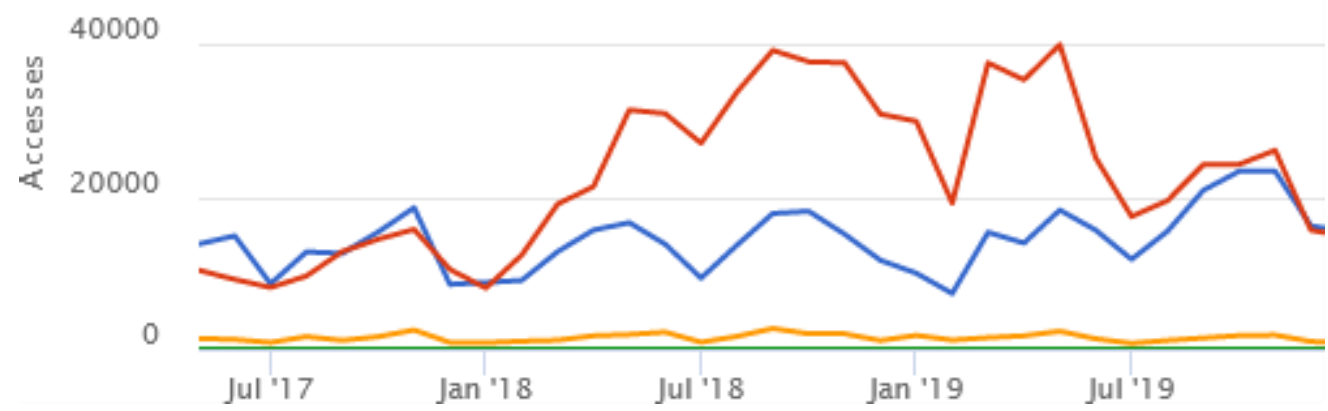




\section{Proposta de solução}

Trata-se da construção de óculos inteligentes (smartglasses) para averiguação constante acerca da condição atual do estoque.

Utilizando uma etiqueta padronizada contendo o nome do produto, código de barras e cor do cartão correspondente (separadas em 3 cores definidas em vermelho, verde ou azul), o óculos está equipado com o detector de cores e leitor, onde o usuário precisa olhar para a etiqueta para que os dados sejam atualizados no banco de dados. Representado na Tabela 1 como:

Tabela 1 - Representação de etiqueta para nomeação dos produtos

\begin{tabular}{|l|l|l|}
\hline Nome do produto & Código de barras & Cor do cartão \\
\hline
\end{tabular}

Fonte: Autores (2021)

Estruturalmente construído a partir do polímero sintético termoplástico poliácido lático, o material permite que haja contato com a pele e seja impresso em máquinas de impressão 3D, barateando o custo e viabilizando seu uso direto.

Foi realizada a prototipação utilizando um Arduino UNO R3, uma protoboard e um sensor RGB TCS3200, conforme a Figura 3 abaixo:

Figura 3 - Circuito prototipado

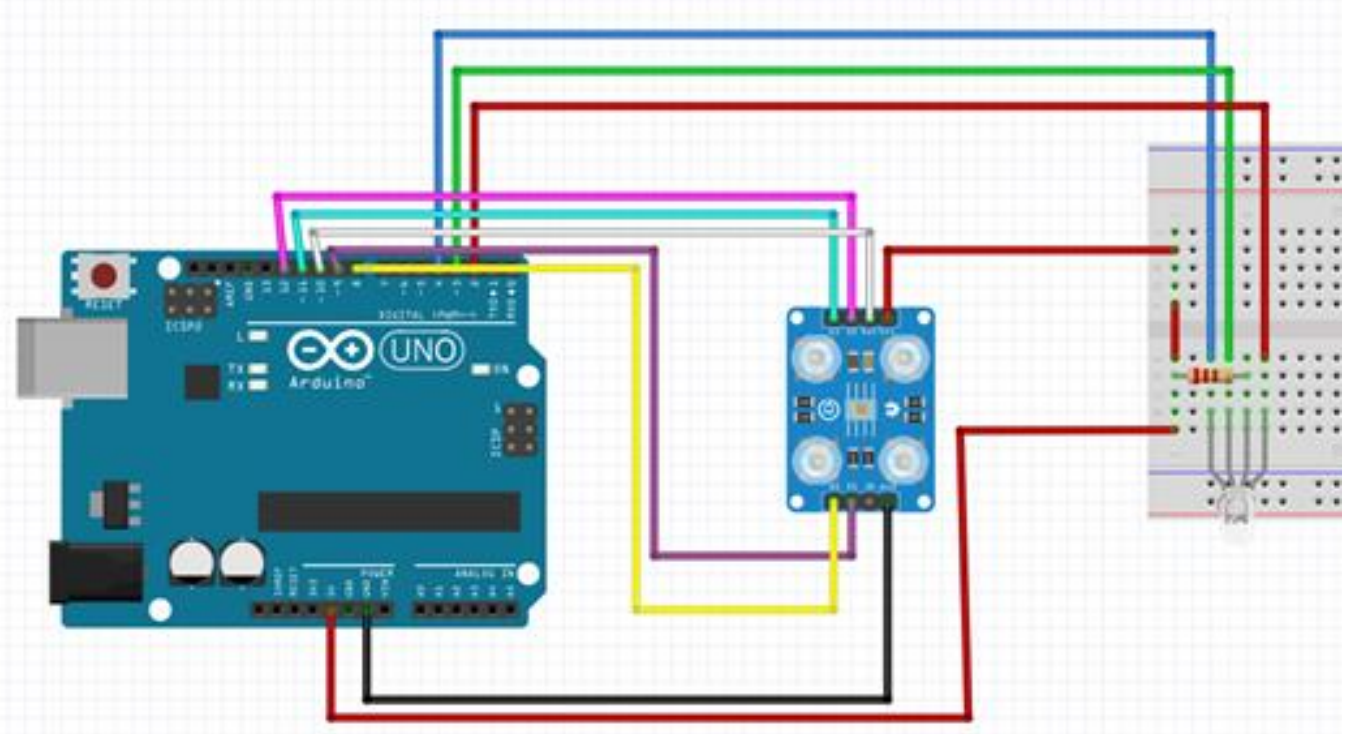

Fonte: Autores (2021) 
A título de organização técnica, também foi elaborado o circuito elétrico de forma a obter um segundo nível de visualização além do protótipo construído, conforme representado na Figura 4:

Figura 4 - Visualização do circuito elétrico

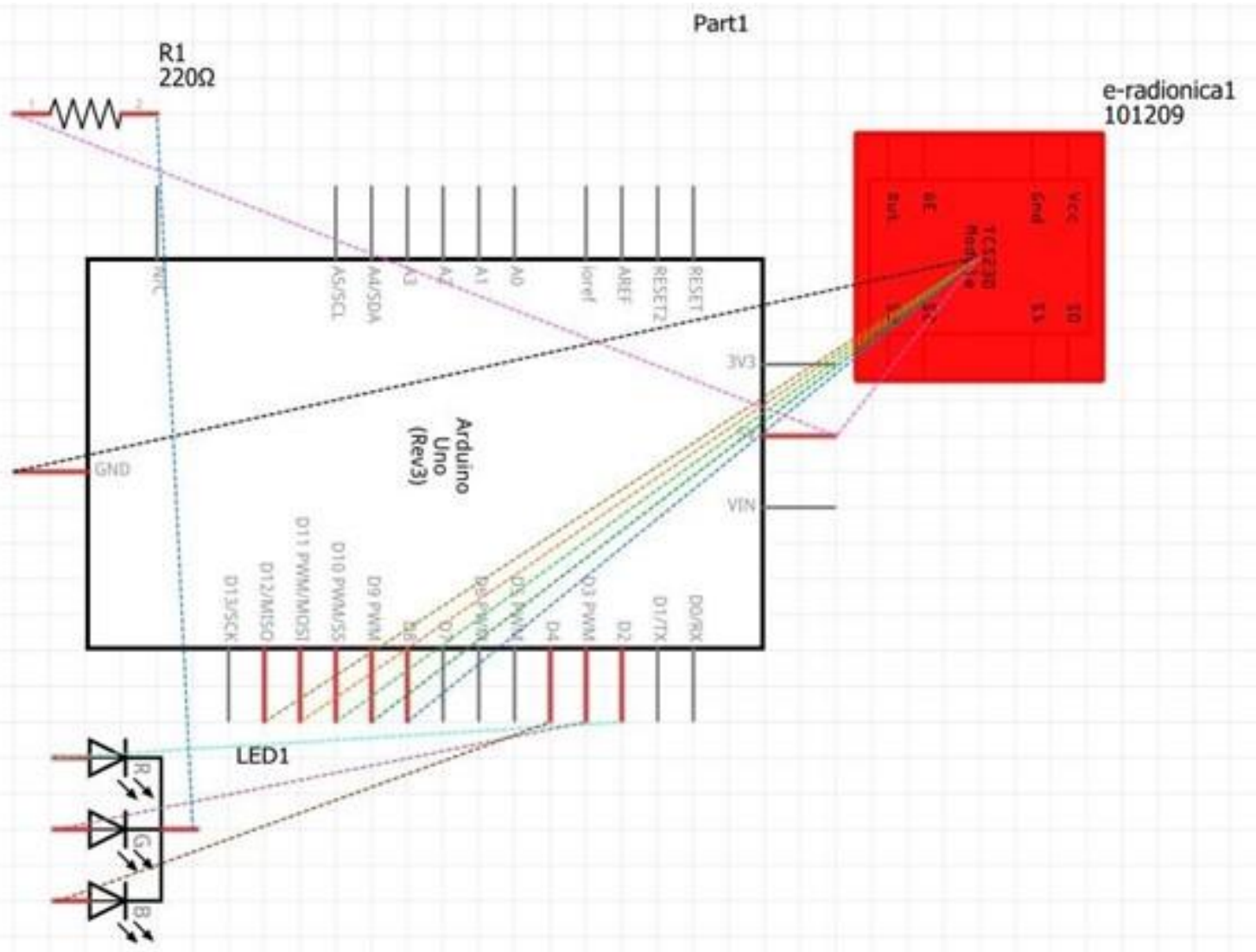

Fonte: Autores (2021)

A experiência de usuário simplificada (Simplified $U X$ ) permite que não haja a necessidade de quaisquer treinamentos ou alterações na organização que pretenda aplicar o Riverstock em seus corredores, uma vez que o fluxo funciona, respectivamente, conforme Figura 5:

Figura 5 - Fluxo de UX

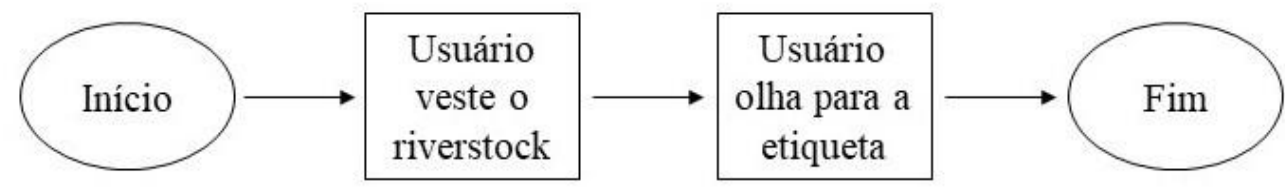


A partir da equação de formulação de cor com captação em RGB, têm-se, em conformidade para com a Equação 1:

$$
\begin{aligned}
C= & \sqrt{2 * \Delta R^{2}+4 * \Delta G^{2}+3 * \Delta * B^{2}} \\
& \text { Algoritmo para captação de cores }
\end{aligned}
$$

Algoritmo escrito em C++, para leitura das cores em RGB utilizando o sensor TCS3200 como input no circuito, conforme demonstrado na Figura 6:

Figura 6 - Captação de cores

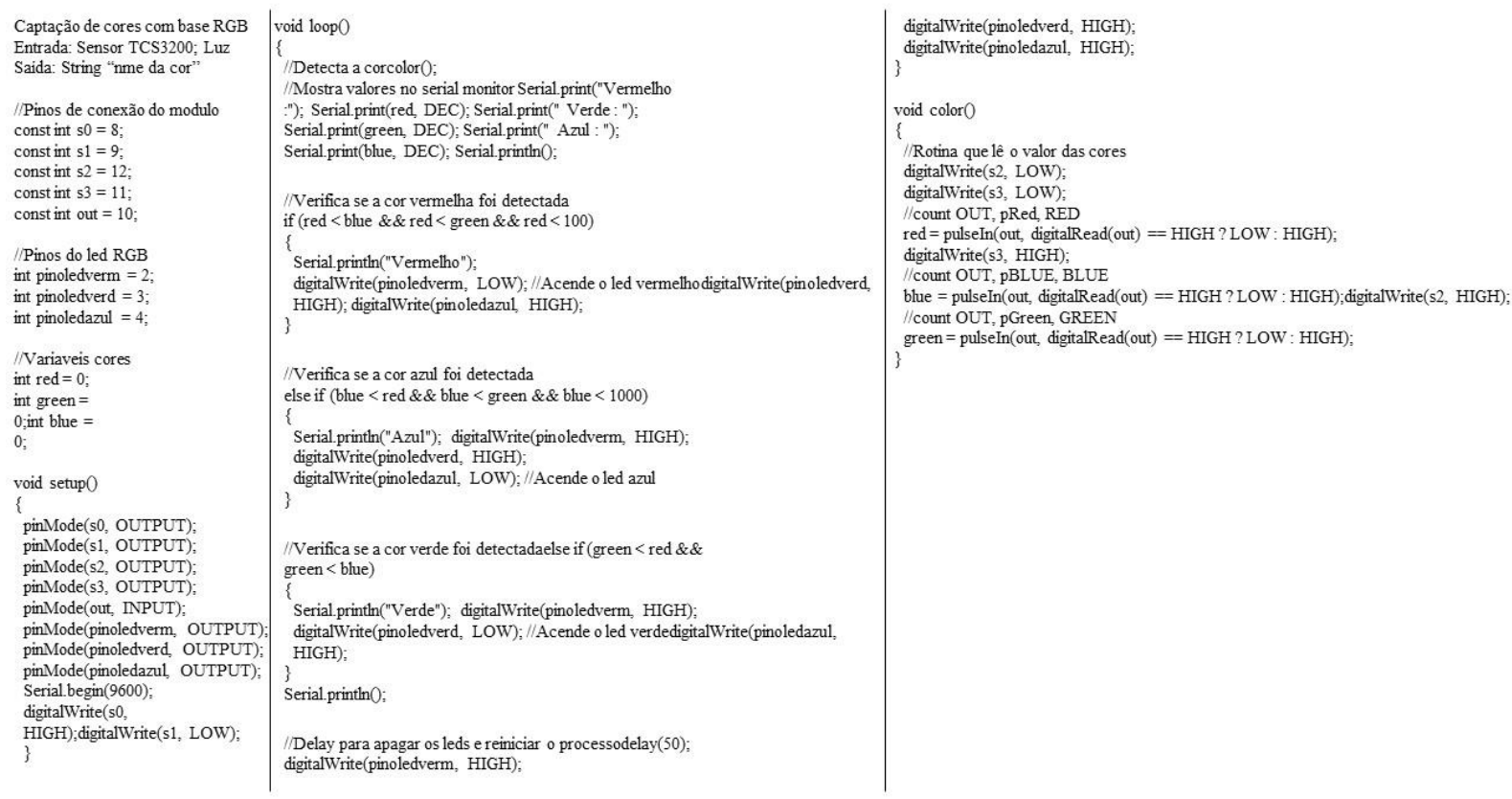

Fonte: Autores (2021)

Por conseguinte, a reunião dos conhecimentos anteriores acoplar-se-ão no interior da estrutura física do Riverstock, que irá realizar a leitura de forma automática, atuando como um observador digital através de um observador (pessoa), onde o fluxo de informação corre da seguinte forma, representado na Figura 7: 


\section{Prateleira}

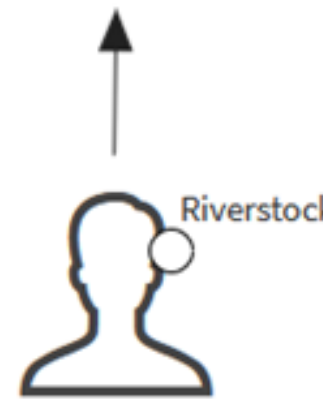

Observador

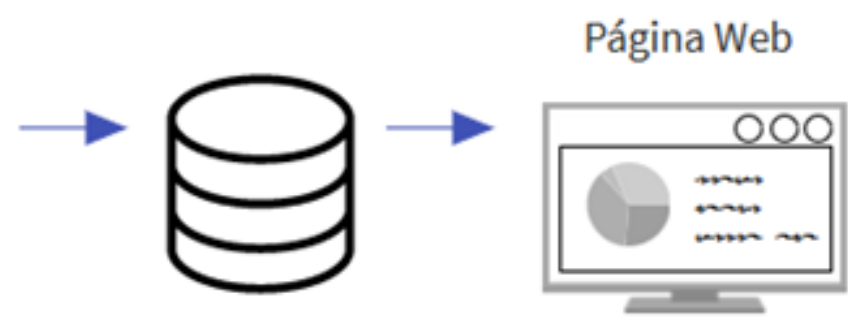

Banco de dados
Fluxo de informação

Fonte: Autores (2021)

O observador - geralmente o manipulador de estoque -, ao utilizar o Riverstock, olha para as etiquetas correspondentes (estas, seguindo o padrão mencionado) e o dispositivo captura a situação atual do produto e a relaciona numa matriz, presente no banco de dados.

Essa matriz é também a base de uma página web de acesso privilegiado com informações atualizadas acerca da situação do estoque do produto mencionado.

Por conseguinte, Riverstock amplia e facilita o poderio do chão de fábrica ao tornar intuitivo o processo de registro de dados (visto que o ato será reduzido apenas ao de olhar para a etiqueta disposta na prateleira) somado à integração com os responsáveis da alta administração (visto que os dados permanecem acessíveis numa página web, sendo possível realizar as buscas através de qualquer dispositivo leitor de linguagens web).

\section{Resultados alcançados}

O objetivo deste trabalho está pautado na viabilidade de aplicação de um produto inovador, de custo baixo e entrega de valor também - relativamente - baixa no mercado, com impactos no faturamento significativos a partir do primeiro mês de uso na organização, sem que haja a 
necessidade de mudanças na cultura organizacional, sendo uma aplicação de uso imediato, dispensando treinamentos e mutações na estrutura organizacional.

O primeiro conceito está na viabilidade de solução, ou seja, se, em teoria, é possível criar um produto capaz de realizar este tipo de atividade. Após estudar o corpo do problema através do mapa cognitivo (Figura 1), verificou-se a viabilidade.

O próximo conceito definido está na viabilidade técnica, portanto, se, em teoria, existe um produto tecnicamente viável e passível de aplicação nos tempos atuais, utilizando tecnologias já existentes, de forma em que a aplicação seja sustentável e, posteriormente, escalável.

Em seguida averiguou-se a possibilidade de tornar este produto acessível a usuários sem qualquer tipo de conhecimento com dispositivos de tecnologia da informação, onde a interface e experiência de usuário (UI/UX) seja tão intuitiva a ponto de não exigir qualquer tipo de manual de utilização, bastando utilizar o produto com noções básicas humanas.

Ao atender estes conceitos, por conseguinte, verificou-se a capacidade de replicação deste mesmo produto em $\mathrm{N}$ organizações, ou seja, não estar restrito apenas a um tipo de ambiente, onde sua aplicação pode estar presente em ambientes mais conservadores e inflexíveis (como organizações militares) e, ao mesmo tempo, em meios mais abertos mutáveis, como startups contemporâneas. Conforme representado na Figura 8, cria-se o conceito de produto:

\section{Figura 8 - Representação do resultado}

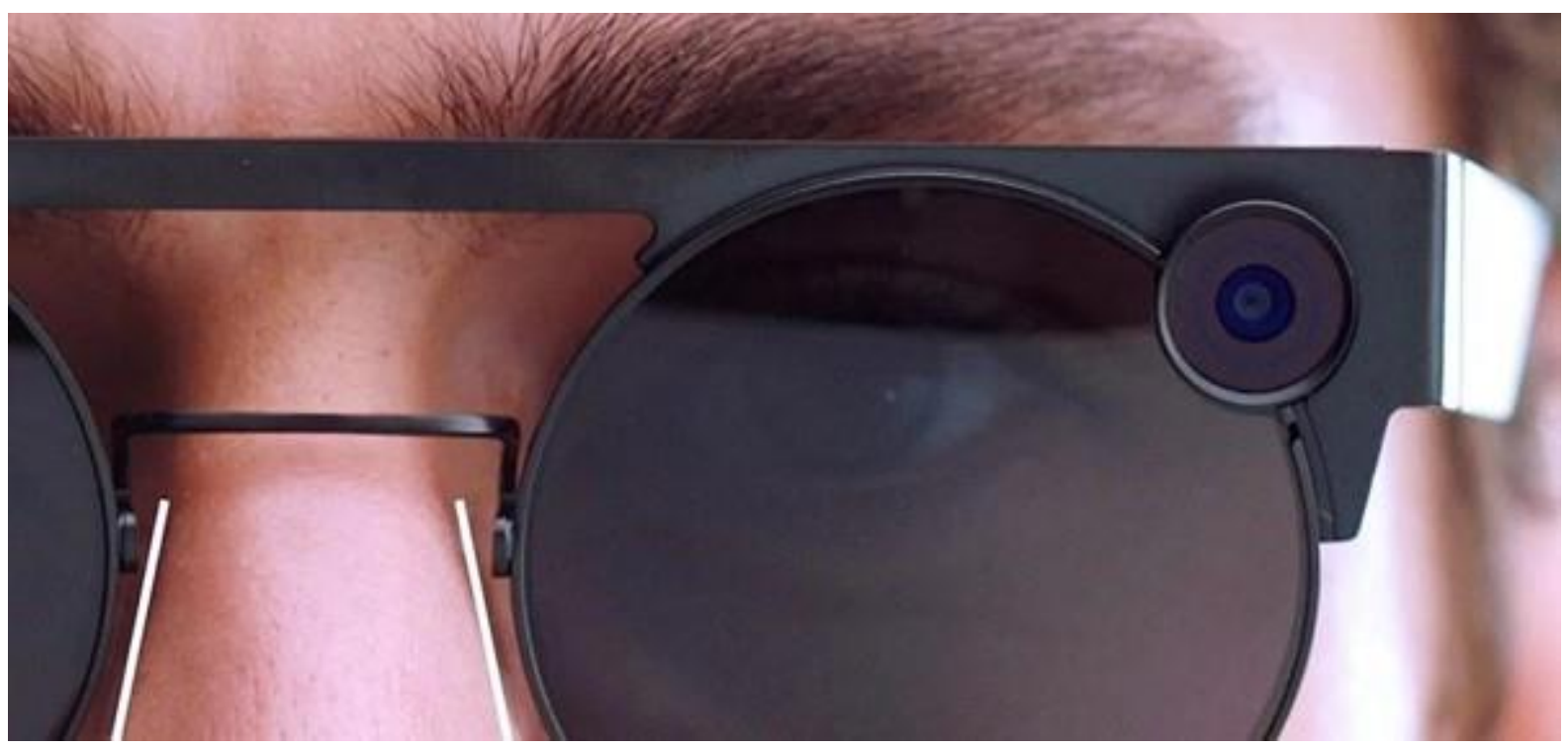

Fonte: "HTC Vive Concept Smartglasses", phoneweek.co.uk (2021)

Riverstock foi o produto capaz de passar em todos estes critérios, onde, através deste trabalho, é possível comprovar sua viabilidade de aplicação em todos os ambientes organizacionais 
detentores de ativos econômicos em estoques, desde as pequenas lojas até grandes indústrias com processos bem definidos.

O design de interface voltado para intuição permite que Riverstock seja aplicado em todo tipo de ambiente, sem a necessidade de treinamentos ou alterações na organização que o implementar em suas rotinas administrativas.

\section{Discussão dos resultados}

Há de ser compreendido que o produto em questão atende a todos os requisitos dispostos na premissa base da pesquisa, sendo amplamente aplicável, de custo baixo, produção escalável e sustentável, com inovações de processo e otimização do fluxo de informação entre os principais pilares.

Ao utilizar a placa de Arduino UNO e sua extensão identificadora de cores TCS3200, o produto pôde atender às demandas em circuitos reproduzidos por computador, restando sua aplicação prática para colheita de resultados em ambiente não controlado.

Não obstante, é cabível lembrar as possibilidades envolvendo microcomputadores completos, ao invés de placas microcontroladoras, como o Raspberry $\mathrm{Pi}$, já possuindo artefatos como conexão à internet e sistema operacional baseados em Linux. Cabendo discussões de precificação para variabilidade de sua aplicação e uso. A Figura 9 representa este conceito: 


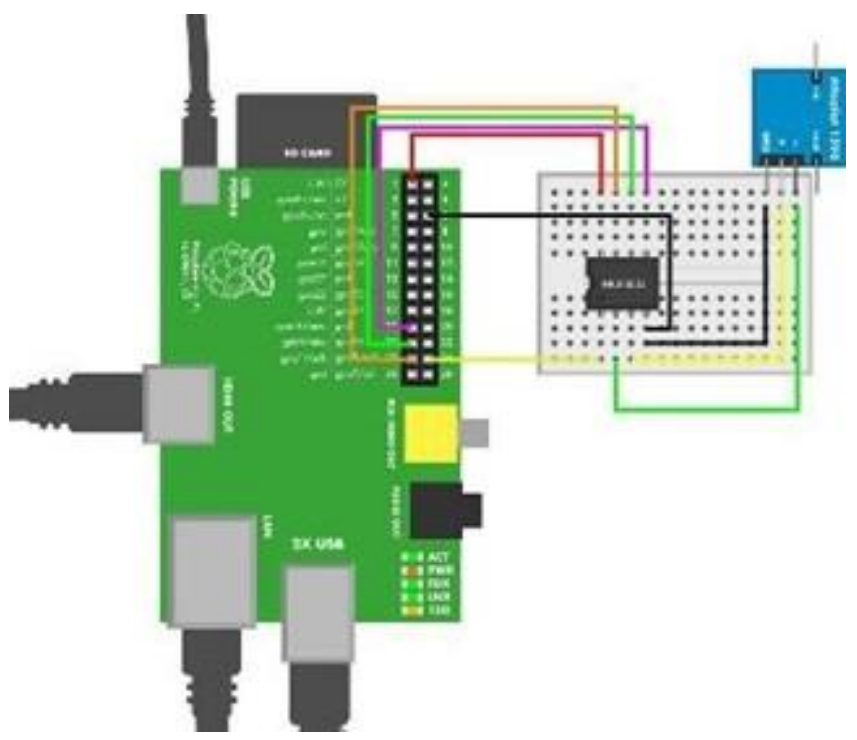

Fonte: Livro “Make:Sensors”, Tero Karvinen, Kimmo Karvinen \& Ville Valtokari (2015)

Por conseguinte, Riverstock mostrou-se como o produto ideal para implementação de solução flexível e escalável, onde o contexto gerencial dentro do universo simbólico demonstra aplicabilidade factível no mundo real (entre modelagens e resultados), onde as decisões prováveis não são oriundas da zona metafísica, mas fundamentada. Em conformidade para com Figura 10:

Figura 10 - Mundo real X Simbólico

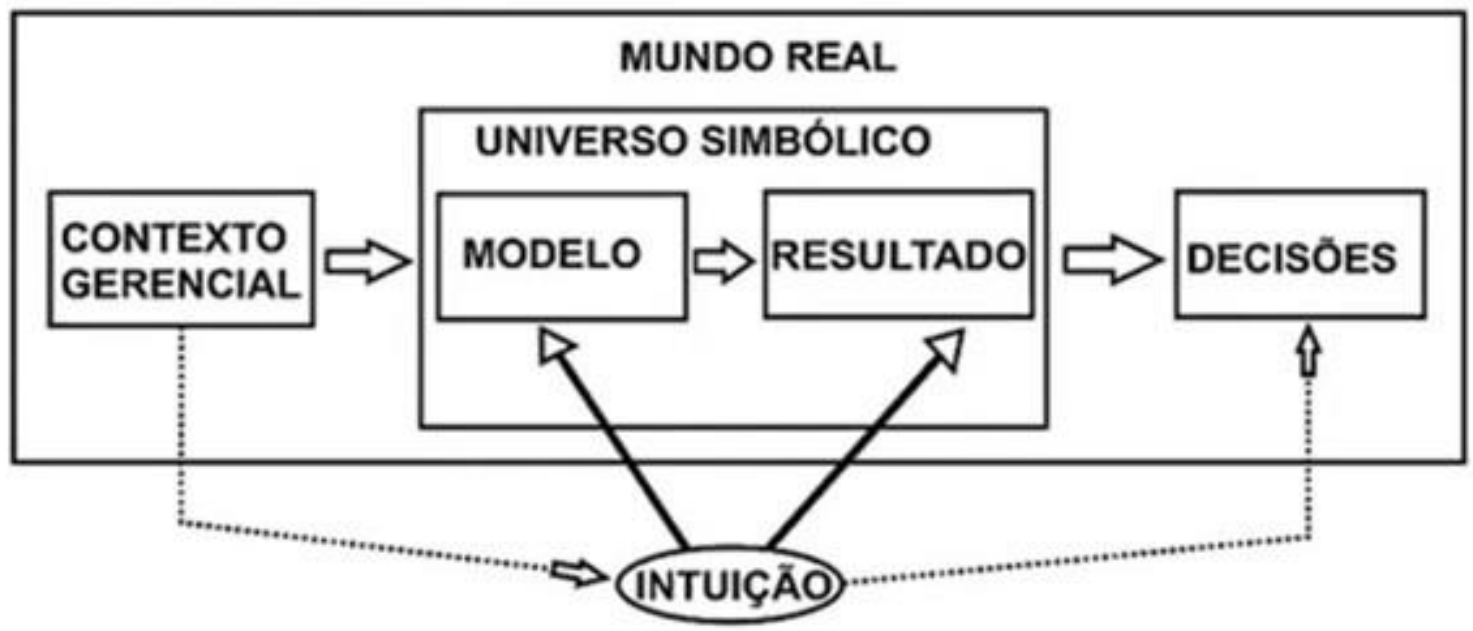

Fonte: Lachtermacher (2009)

\section{Referências}

BRANDALISE L. Administração de materiais e logística. Porto Alegre: Simplissimo Livros Ltda, 2017.

Costa, 2017. Gestão de estoque: estudo de caso sobre previsão de demanda em uma microempresa fabricante de materiais esportivos. Artigo da Revista Fatec Zona Sul. 
Dandaro, F., \& Martello, L. L. (2015). Planejamento e controle de estoque nas organizações. Revista Gestão Industrial, 11(2).

DANTAS, July Caroline de Araújo. A importância do controle de estoques: Estudo realizado em um supermercado. Trabalho de Conclusão de Curso realizado na Universidade Federal do Rio Grande do Norte em Caicó/RN. 2015.

De Oliveira, P. C. S., de Lima, L. E. S., dos Santos Silva, E. C., Aragao, L. K. V., \& de Carvalho Monte, F. (2016) CONTROLE DE ESTOQUE COMO FERRAMENTA DE APOIO GERENCIAL: UM ESTUDO DE CASO EM UMA LOJA DE CONVENIÊNCIA NA CIDADE DE SUMÉ/PB. Artigo presente nos Anais do XXXVI Encontro Nacional de Engenharia de Produção.

DE SOUSA, CRISTIANO LIZ. "IMPLANTAÇÃO DE CONTROLE DE ESTOQUE NA EMPRESA GJA PRODUTOS DE LIMPEZA Lages." Revista Uniplac - REPOSITÓRIOS DE RELATÓRIOS-Engenharia de Produção 2 (2017).

Dos Santos, Tiago Silva, et al. "APLICAÇÃO DE FERRAMENTAS DA GESTÃo DE ESTOQUE E CUSTO: UM ESTUDO DE CASO EM UMA LOJA DE ARTIGOS E ACESSÓRIOS PARA AUTOMÓVEIS EM MARABÁ-PA." Revista Latino-Americana de Inovação e Engenharia de Produção 5.8 (2017): 98-116.

FENERICH, F. C. Administração dos sistemas de operações. Biblioteca Universitária Virtual. Curitiba: Inter Saberes, 2016.

LÉLIS, Eliacy Cavalcanti. (Org.). Administração de materiais. São Paulo: Pearson Education do Brasil, 2016. Biblioteca virtual universitária.

MARTELLI, L. L.; DANDARO, F. Planejamento e controle de estoque nas organizações.Paraná: Revista Gestão Industrial, 2015.

Oliveira, Christie \& Jelinek, Andrea \& Chemale Junior, Farid \& Bernet, Matthias. (2016). Oliveira et al 2016. PAOLESCHI, B. Almoxarifado e gestão de estoque:do recebimento, guarda e expedição à distribuição do estoque. 2. ed. São Paulo: Érica, 2018.

Peres, Simone Ribeiro. "Avaliação de implantação da ferramenta de controle de estoques curva ABC em uma empresa de comercialização de produtos agropecuários." Trabalho de Conclusão de Curso realizado no Instituto Federal Goiano em 2020.

SILVA, M. G.; RABELO, M. H. S. Importância do controle de estoques para as empresas. Minas Gerais: Revista Acadêmica Conecta FASF, 2017.

Teixeira, T. A., \& Vernini, A. A. (2016, September). CURVA ABC COMO FERRAMENTA PARA A GESTÃO DE ESTOQUE DE UMA DOCERIA. In V JORNACITEC. 